S. Györik

S. Erni et al.

\section{Follow-up prolongado da talcagem via toracoscopia no pneumotórax espontâneo primário}

\section{Long-term follow-up of thoracoscopic talc pleurodesis for primary spontaneous pneumothorax}

\section{Resumo}

O pneumotórax espontâneo primário (PEP) afecta particularmente indivíduos jovens, existindo normas de tratamento internacionais desta patologia que não são aplicadas uniformemente nos diferentes países. A talcagem via toracoscopia sob anestesia local e sedação é segura e apresenta resultados de eficácia superiores em relação ao tratamento conservador com dreno pleural no PEP, que não se resolve com a simples drenagem.

Os autores deste artigo defendem que no PEP recidivante ou num primeiro episódio de PEP, em que a saída de ar seja superior a 48 horas, é necessária uma abordagem mais agressiva, de preferência a talcagem por toracoscopia. A toracoscopia permitiria simultaneamente a visualização de possíveis aderências, blebs ou bolhas.

Existe um estudo que refere alterações da função pulmonar, nomeadamente a restrição e espessamento pleural, após talcagem, no PEP. Contudo, este estudo não refere o tipo e a dose de talco utilizado, a técnica de pleurodese realizada, nem o método radiológico de quantificação da pleura envolvida.

Pela controvérsia existente em torno da talcagem e seus eventuais efeitos adversos, os autores deste estudo realizaram um follow-up a longo prazo (em média 118 meses), em doentes com PEP recidivante ou persistente por um período superior a 48 horas e que foram submetidos a pleurodese com talco, via tora- coscopia com anestesia local e sedação. Os parâmetros avaliados foram a carga tabágica, a clínica, a taxa de recorrência e a função pulmonar destes doentes. O talco utilizado era francês, de dimensões padronizadas (mais de $50 \%$ das partículas superiores a $10 \mu \mathrm{m}$ ) e livre de asbestos.

Um total de 112 doentes foram submetidos a talcagem, conseguindo-se obter um follow-up em 63 casos (56\%). A taxa de sucesso da pleurodese foi de $95 \%$ nos doentes avaliados. A recorrência de pneumotórax ocorreu em 3 doentes que mantiveram hábitos tabágicos (5\%) aos 2 meses, 1 e 10 anos após talcagem, tendo estes doentes sido submetidos posteriormente a pleurectomia cirúrgica. De salientar que $62 \%$ dos doentes permaneceram fumadores no período de follow-up.

A comparação da função pulmonar entre fumadores e não fumadores foi a esperada, com uma redução do VEMS e índice de Tiffeneau no grupo dos fumadores. A capacidade vital forçada média foi de 102\%, com capacidade total pulmonar de $99 \%$ na altura do follow-up. Os autores deste estudo concluem pois que a pleurodese com talco, via toracoscopia, no PEP, é um procedimento eficaz e seguro a longo prazo, sem implicar alterações da função pulmonar, nos doentes não fumadores. Concluem ainda que só em doentes com blebs ou bolhas com um diâmetro superior a $2 \mathrm{~cm}$ a melhor abordagem seria a cirúrgica.

Eur Respir J 2007;29: 757-760. 


\section{Comentário}

A abordagem terapêutica do PEP recorrente permanece controversa. A controvérsia está particularmente relacionada com a utilização do talco para pleurodese. Os grandes opositores para a sua utilização são principalmente norte-americanos, país onde o talco utilizado tem dimensões inferiores a $5 \mu \mathrm{m}$ e onde surgiram vários casos de SDRA (síndroma de dificuldade respiratória no adulto) após a talcagem. Na Europa, as partículas de talco utilizado têm dimensões superiores a $10 \mu \mathrm{m}$, não exitindo nas séries europeias a descrição de casos de SDRA.

Este artigo vem mais uma vez demonstrar a elevada eficácia da pleurodese com talco, via toracoscopia, sem o aparecimento de complicações graves ou mortalidade. Tem ainda a grande vantagem de ser um estudo de follow-up a longo prazo (média superior a 10 anos) pós-pleurodese.

Alguns autores têm relatado o aparecimento de síndroma restritiva alguns meses após talcagem no PEP. Este trabalho veio revelar o contrário, apenas mostrando alterações do VEMS nos doentes que mantiveram hábitos tabágicos.

Também a ideia instituída de que a pleurodese com talco impediria um futuro transplante pulmonar ou intervenção torácica tem vindo a ser desmistificada por diferentes trabalhos publicados. Uma intervenção torácica após talcagem é mais complicada tecnicamente, mas não impossível. Inclusive, neste artigo os três doentes que recidivaram o pneumotórax após talcagem foram submetidos a cirurgia torácica posterior.

Um largo estudo do cirurgião cardiotorácico Cardilllo, com 861 doentes submetidos a talcagem via VATS ( cirurgia torácica vídeo assistida) por PEP recidivante, não revelou complicações graves, nomeadamente restrição pulmonar.
Em conclusão, cada vez mais é evidente que a pleurodese com talco via toracoscopia médica é segura e altamente eficaz a longo prazo, no PEP recorrente ou persistente. $\mathrm{Na}$ presença de bolhas com dimensões superiores a $2 \mathrm{~cm}$, a abordagem cirúrgica permanece a opção mais acertada.

\section{Mensagem}

- O talco esterilizado e livre de asbestos, com partículas com dimensões padronizadas, é seguro e eficaz como agente de pleurodese.

- No pneumotórax espontâneo primário recorrente ou persistente, sem a presença de bolhas superiores a $2 \mathrm{~cm}$, a talcagem via toracoscopia é o método mais eficaz na prevenção de recidiva.

- Não existe a longo prazo evidência de restrição pulmonar após pleurodese com talco

\section{Bibliografia}

1. Shaw $\mathrm{P}$, et al. Pleurodesis for malignant pleural effusions. Cochrane database of systematic reviews. 2004; 1:CD002916.

2. Noppen M. Who's (still) afraid of talc? Eur Respir J 2007; 29:619-621.

3. Cardillo G, et al. Videothoracoscopic treatment of primary spontaneous pneumothorax: a 6- year experience. Ann Thorac Surg 2000; 69:357-361.

4. Lange $\mathrm{P}$, et al. Lung function 22-35 years after treatment of idiopathic spontaneous pneumothorax with talc poudrage or simple drainage. Thorax 1988; 43:559-561. 5. Cardillo G, et al. Videothoracoscopic talc poudrage in primary spontaneous pneumothorax: a single-institution experience in 861 cases. J Thorac Cardiovasc Surg 2006; 131:322-328.

Paula Monteiro 07.09.30 